\title{
Transcriptional response of the heat shock gene hsp70 aligns with differences in stress susceptibility of shallow-water corals from the Mediterranean Sea
}

\author{
Silvia Franzellitti ${ }^{\mathrm{a}, * 1}$, Valentina Airi $^{\mathrm{b}, 1}$, Diana Calbucci $^{\mathrm{a}}$, Erik Caroselli ${ }^{\mathrm{b}}$, Fiorella Prada ${ }^{\mathrm{b}}$, \\ Christian R. Voolstra ${ }^{c}$, Tali Mass ${ }^{\mathrm{d}}$, Giuseppe Falini ${ }^{\mathrm{e}}$, Elena Fabbri ${ }^{\mathrm{a}}$, Stefano Goffredo ${ }^{\mathrm{b}}$ \\ a Animal and Environmental Physiology Laboratory, Department of Biological, Geological and Environmental Sciences, University of Bologna, via S. Alberto 163, 1-48123, \\ Ravenna, Italy \\ ${ }^{\mathrm{b}}$ Marine Science Group, Department of Biological, Geological and Environmental Sciences, University of Bologna, Via F. Selmi 3, I-40126, Bologna, Italy \\ ${ }^{\mathrm{c}}$ Red Sea Research Center, Division of Biological and Environmental Science and Engineering (BESE), King Abdullah University of Science and Technology (KAUST), \\ Thuwal, 23955-6900, Saudi Arabia \\ d Department of Marine Biology, The Leon H. Charney School of Marine Sciences, University of Haifa, Multi Purpose Boulevard, Mt. Carmel, Haifa, 3498838, Israel \\ 'Department of Chemistry “Giacomo Ciamician”, University of Bologna, via F. Selmi 2, 1-40126, Bologna, Italy
}

A R T I C LE INFO

Keywords:

Thermal stress

Coral

Gene expression

Heat shock protein

Physiological plasticity

Climate change

\begin{abstract}
A B S T R A C T
Shallow-water corals of the Mediterranean Sea are facing a dramatic increase in water temperature due to climate change, predicted to increase the frequency of bleaching and mass mortality events. However, supposedly not all corals are affected equally, as they show differences in stress susceptibility, as suggested by phy. siological outputs of corals along temperature gradients and under controlled conditions in terms of reproduction, demography, growth, calcification, and photosynthetic efficiency. In this study, gene expression and induction of a 70-kDa heat shock protein (HSP70) was analyzed in five common shallow-water hard corals in the Mediterranean Sea, namely Astroides calycularis, Balanophyllia europaea, Caryophyllia inornata, Cladocora caespitosa, and Leptopsammia pruvoti. The main aim was to assess the contribution of this evolutionary conserved cytoprotective mechanism to the physiological plasticity of these species that possess different growth modes (solitary $v s$ colonial) and trophic strategies (zooxanthellate $v$ s azooxanthellate). Using quantitative real-time PCR, in situ hsp70 baseline levels and expression profiles after a heat-shock exposure were assessed.

Levels of $h s p 70$ and heat stress induction were higher in zooxanthellate than in azooxanthellate species, and different heat stress transcriptional profiles were observed between colonial and solitary zooxanthellate corals. On the whole, the $h s p 70$ transcriptional response to heat stress aligns with stress susceptibility of the species and suggests a contribution of trophic strategy and morphology in shaping coral resilience to stress. Understanding these molecular processes may contribute to assess the potential effects and relative resilience of Mediterranean corals under climate change.
\end{abstract}

\section{Introduction}

Marine ecosystems are declining worldwide due to global climate change and other anthropogenic impacts (Hughes et al., 2018). These rapid changes alter the structure of habitats and communities and cause the loss of many species. Of particular concern is the decline of scleractinian corals triggered by thermal stress (Hoegh-Guldberg et al., 2007). Rising sea surface temperature is linked to coral bleaching and mass mortality events in both symbiotic and non-symbiotic corals in the tropics and in the Mediterranean Sea (Altieri et al., 2017; Jimenez et al., 2016; Rodolfo-Metalpa et al, 2006b), The Mediterranean Sea is warming at two to three times the rate for the global ocean (VargasYáñez et al., 2008), showing an increased occurrence of hot extremes by $200-500 \%$ throughout the region (Diffenbaugh et al., 2007). This is due to its position in the transition between the arid climate of North Africa and the temperate climate of central Europe, which renders Mediterranean climate vulnerable to even relatively moderate modifications of the general circulation (Giorgi and Lionello, 2008). Furthermore, its

\footnotetext{
* Corresponding author.

E-mail address: silvia.franzellitti@unibo.it (S. Franzellitti).

${ }^{1}$ These authors equally contributed to the work performed.
} 
semi-enclosed nature and the restricted water exchanges with the Atlantic Ocean results in a hydrological residence time of about 100 years and a great capacity to store heat (Diffenbaugh et al., 2007). Indeed, climatic models predict a rapid average warming in the Mediterranean region (about $2.5^{\circ} \mathrm{C}$ over the $21^{\text {st }}$ century under the RCP8.5 projection; Shaltout and Omstedt (2014)) along with a greater occurrence of extreme temperature events (Giorgi and Lionello, 2008). Under such a scenario, not all corals are thought to be affected equally: during mass coral bleaching events, survival of scattered colonies suggests that some groups of corals may possess inherent physiological tolerance to environmental stress (Marshall and Baird, 2000; Oliver and Palumbi, 2011; West and Salm, 2003). Therefore, questions remain about the underlying mechanisms leading to differences in thermal tolerance, and about the relative contributions of genotypic adaptation (where selection drives differences in susceptibility over evolutionary times scales), and phenotypic acclimatization (where organisms respond to extremes using their existing genomic repertoire) (Palumbi et al., 2014).

Changing environmental conditions may be physiologically tolerable, allowing acclimatization or adaptation, or may be intolerable, promoting change in phenology (timing of annual events), or massive bleaching, death and local extinction (Parmesan, 2006). Physiological performances and responses are the principal determinant of a species tolerance to environmental variability and, as such, they may change the ability of individual corals to cope with changing conditions (Somero, 2012). Physiological plasticity describes the process of tuning phenotypic traits of organisms within their lifetime allowing them to live in varying environments (Gates and Edmunds, 1999). In this regard, investigations of the regulatory mechanisms governing stress responses by monitoring changes of mRNA expression profiles may provide early-warning molecular markers of physiological plasticity and represent an important source of information on the mechanisms underlying the differences in coral physiological resilience (Dixon et al., 2015; Poli et al., 2017; Seneca and Palumbi, 2015).

Although studies on tropical corals disclosed some molecular mechanisms underlying acclimatization and coordinated modulation of gene expression as a reaction to environmental stress (Bay and Palumbi, 2017; Bellantuono et al., 2012; Gutner-Hoch et al., 2017; Maor-Landaw et al., 2014), similar information on temperate corals of the Mediterranean Sea are largely lacking. To fill this gap, the present study assessed expression of a $h s p 70$ gene product under baseline and heat stress conditions in five Mediterranean shallow-water coral species representing different growth modes (colonial: Astroides calycularis and Cladocora caespitosa; solitary: Balanophyllia europaea, Caryophyllia inornata, and Leptopsammia pruvoti) and trophic strategies (zooxanthellate: B. europaea and C. caespitosa; azooxanthellate: A. calycularis, C. inornata, and L. pruvoti) (Fig. 1). An overview of population dynamics and physiological traits (i.e., reproduction, linear extension rate, net calcification, and photosynthetic efficiency) of these species in relation to increasing temperature is provided in Fig. 1, as a means to infer their relative tolerances to stress. For example, azooxanthellate species $C$. inornata and $L$. pruvoti seem quite tolerant to temperature increases compared to their sympatric zooxanthellate species B. europaea and $C$. caespitosa, while $A$. calycularis responds negatively to increasing temperatures (Fig. 1).

The 70-kDa heat shock proteins (HSP70s) are molecular chaperones and have vital cytoprotective functions (Feder and Hofmann, 1999) They are involved in protein folding, unfolding, sorting transport, and assembly of complexes. They also protect cells from apoptosis and proteotoxic stressors (Hartl et al., 2011). During exposure to elevated temperatures, protein misfolding, aggregation or disruption of regulation and disassembly of multiprotein complexes may occur, leading to subsequent activation of signaling pathways triggering a stress-related HSP70 induction (Richter et al., 2010). Through their cytoprotective functions, HSP70 are thought to restore proteolytic homeostasis.

HSP70s are broadly studied, highly conserved molecular mediators of environmental acclimatization in marine organisms (Fabbri et al.
2008; Morris et al., 2013), and amongst the primary early responders to stress in corals (Louis et al., 2017; Traylor-Knowles et al., 2017). As a consequence, many studies assessed hsp70 expression in tropical corals under different abiotic and biotic cues, including temperature (MaorLandaw et al., 2014; Seveso et al., 2014; Zhang et al., 2018), pH/pCO (Moya et al., 2015), salinity (Ellison et al., 2017), pollutants (Jovanovié and Guzmán, 2014; Overmans et al., 2018; Venn et al., 2009), bacterial infections (Brown et al., 2013; Seveso et al., 2016), or host-symbiont interplay to maintain holobiont homeostasis (Levy et al., 2011; Rosic et al., 2014b). These studies suggest that cnidarian hsp70 gene expression and function is similar across multiple stressors and comparable to vertebrates (Kvitt et al., 2016). Furthermore, hsp70 up-regulation at the initial stage of the stress response appears to be a common protective mechanism to avoid the onset of severe pathological conditions or to postpone bleaching (Maor-Landaw et al., 2014; Rosic et al., 2014a).

Studies on hsp70 expression in relation to environmental variables or to symbiosis in Mediterranean corals are lacking, and hsp70 sequences are not available for the species investigated in this study. An exception is represented by $B$. europaea, for which a recent investigation based on whole transcriptome sequencing reported $h s p 70$ transcriptional response to temperature and $\mathrm{pH}$ combined exposures (MaorLandaw et al, 2017). The comparison with the tropical Stylophora pistillata suggested that $B$. europaea is endowed with more efficient protective and metabolic processes to cope with the high thermal variability of Mediterranean environments (Maor-Landaw et al., 2017). To our knowledge, this is the first study reporting a comparative multispecies analysis of the HSP70 response to thermal stress in temperate corals, which attempts to set the basis for future investigations on the potential regulatory mechanisms behind physiological resilience and acclimatization capabilities in corals from the Mediterranean Sea. We investigated transcriptional regulation of a stress inducible $h s p 70$ by concomitant analysis of expression levels under field conditions and following short-term heat stress experiments, to infer possible influences of peculiar physiological features and diverse life history traits. Gaining this knowledge is a first important step towards understanding the processes involved in species resilience to heat-stress events and may disclose the relevant threats involved in their decline.

\section{Methods}

\subsection{Coral sampling and experimental design}

During May 2016, 60 nubbins (from 6 colonies) of C. caespitosa and 60 polyps of B. europaea, C. inornata, and $L$. pruvoti were collected by SCUBA diving at Calafuria (Leghorn; $43^{\circ} 28.4^{\prime} \mathrm{N}, 10^{\circ} 20^{\prime} \mathrm{E}$ ) (Fig. 2). Nubbins ( 60 from 6 colonies) of A. calycularis were collected at Ponza Island $\left(40^{\circ} 54^{\prime} \mathrm{N} 12^{\circ} 58^{\prime} \mathrm{E}\right)$ (Fig. 2). Samples were collected from sites characterized by high population density at $5-30 \mathrm{~m}$ depth, and all samplings were performed at the same time of the day (early morning), to minimize possible biases due to Hsp70 diel modulation (Levy et al., 2011; Seveso et al., 2018). Upon collection, 12 randomly selected single polyps or fragments of colonies ( 2 nubbins per colony) from each species were immediately immersed in a suitable volume of the RNA later stabilization reagent (Sigma-Aldrich, Milan, Italy) and frozen at $-80^{\circ} \mathrm{C}$ for further analysis of transcriptional levels of coral hsp70 under in situ baseline conditions. The remaining samples were immediately put in refrigerated seawater and transported to the aquarium system of the Department of Biological, Geological and Environmental Sciences (BiGeA) of the University of Bologna. They were acclimatize for 40 days at a constant water temperature of $17{ }^{\circ} \mathrm{C} \pm 0.5^{\circ} \mathrm{C}$ matching the average temperature at the collection sites (Fig. $2 \mathrm{~B}$ and C). Zooxanthellate species (B. europaea and C. caespitosa) were maintained at a photoperiod of $15 \mathrm{~h}: 9 \mathrm{~h}$ light:dark daily cycles to match the natural photoperiod at the collection sites. Azooxanthellate species (A. calycularis, C. inornata, and $L$. pruvoti) were maintained under dimmed light 


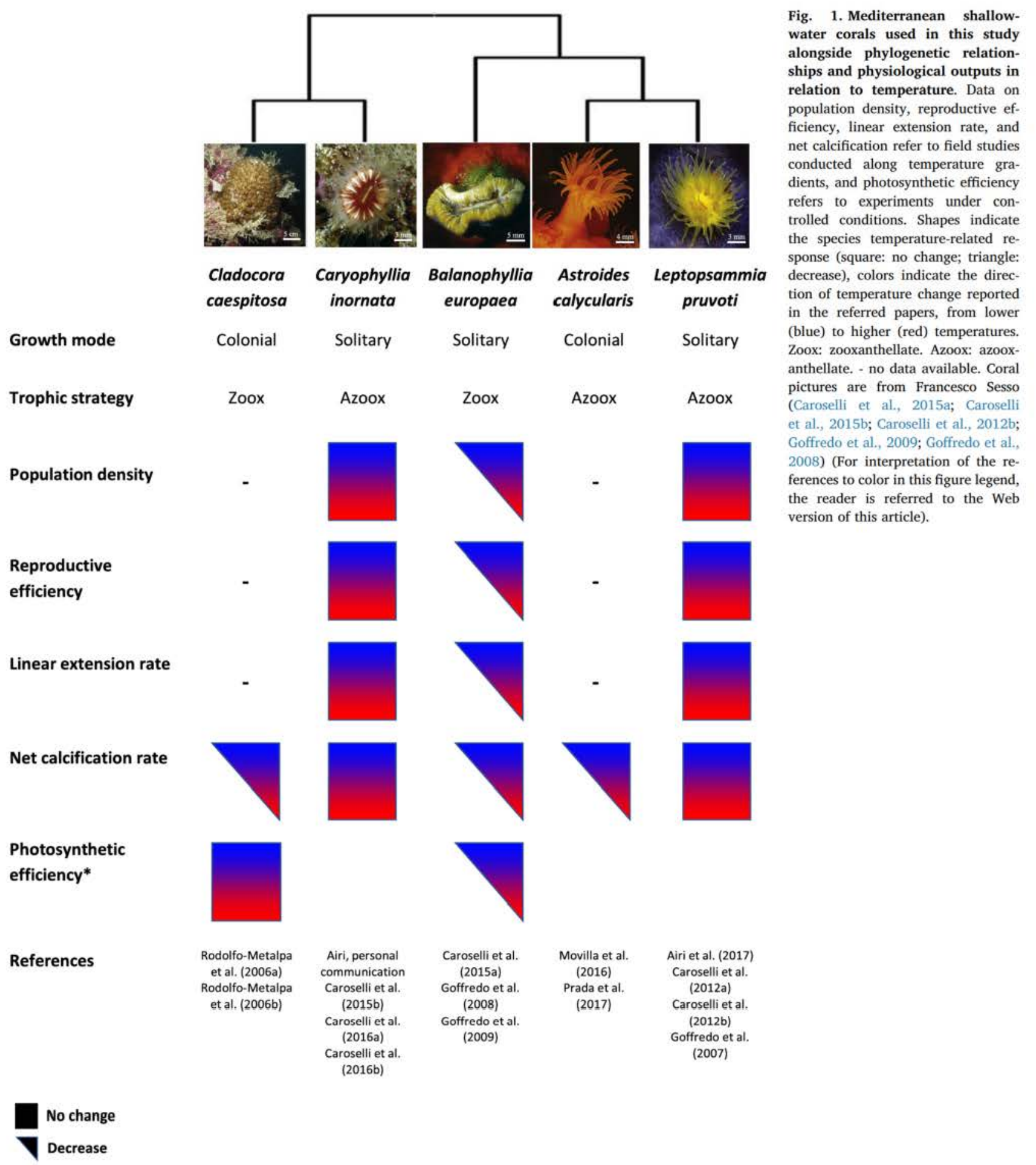

conditions to mimic their natural environment. During the acclimatization period, corals were fed twice a week with a commercial plankton preparation (Elos Coral Foods SvC).

Thermal stress experiments were performed using a short-term heat shock treatment at a relatively high temperature (here $32^{\circ} \mathrm{C}$, about $5^{\circ} \mathrm{C}$ above average ambient values) followed by $0-24 \mathrm{~h}$ of post-stress recovery at the coral acclimatization temperature (Fig. 3). This exposure scheme and experimental parameters were selected according to our past experience on marine invertebrate investigations on the HSP70 response (Franzellitti and Fabbri, 2005; Piano et al., 2005, 2004). Briefly, this experimental setup was chosen to analyze the different capabilities of the selected species to promptly increase $h s p 70$ transcription within short-term intense heat stress exposures. It also accounts for the specific regulatory features of stress-inducible Hsp70s, 


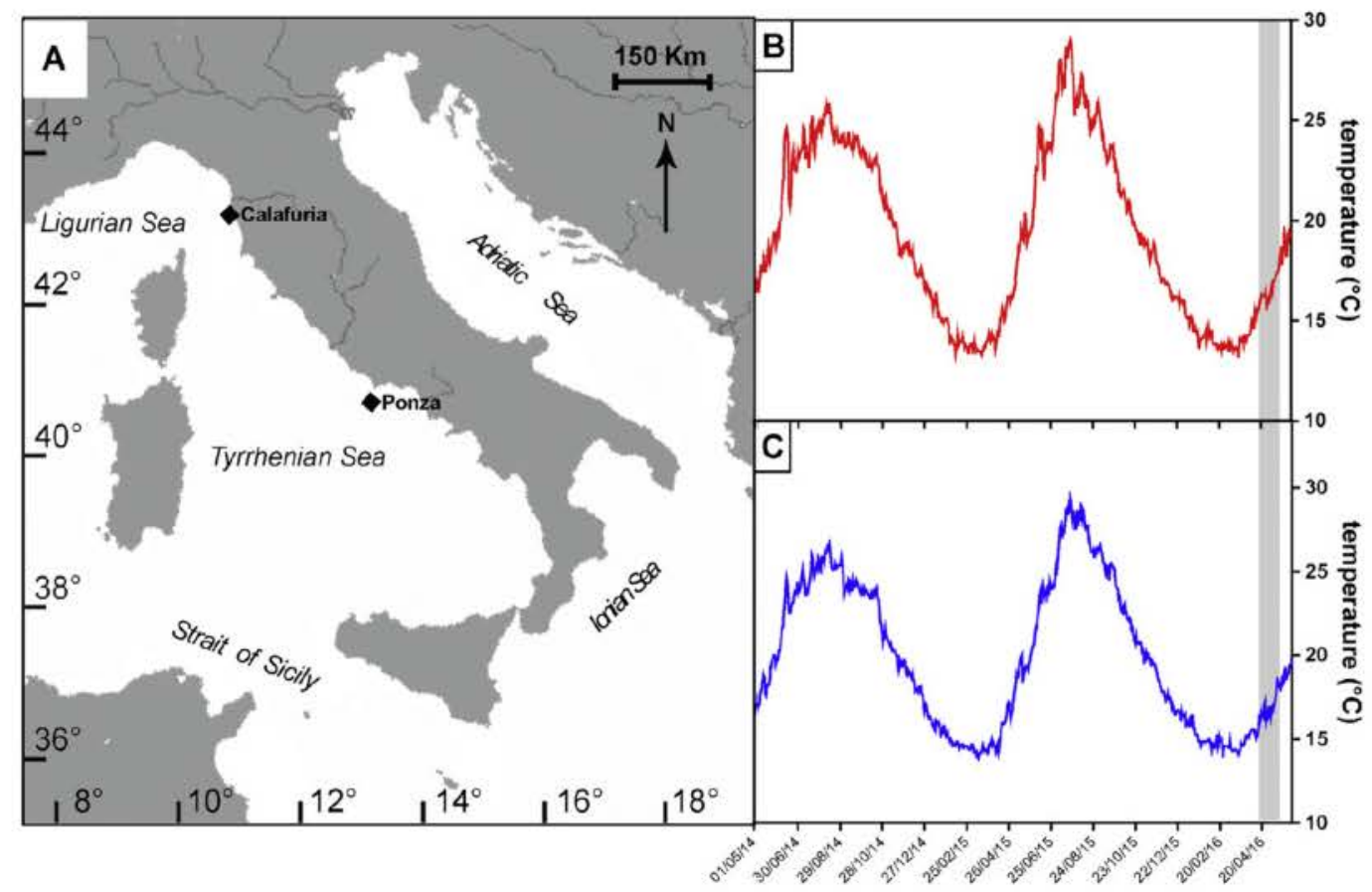

Fig. 2. Map of the sampling sites at Calafuria and Ponza Island (Thyrrenian Sea, Italy). (A) The map of the sampling locations was generated using the OpenStreetMap database (http://www.openstreetmap.org/copyright). Mean satellite-derived daily sea surface temperature (SST) profiles at (B) Calafuria and (C) Ponza sampling locations (across a 2-year period spanning the sampling time point) were retrieved using the Copernicus Marine Service Product (http://marine. copernicus.eu/), and visualized through Panoply ver 4.8 (http://www.giss.nasa.gov/tools/panoply/). Sampling period is showed (grey area). Average SSTs within the sampling period were (mean $\pm \mathrm{SD}$ ) $16.9 \pm 0.5^{\circ} \mathrm{C}$ (Calafuria) and $17.4 \pm 0.7^{\circ} \mathrm{C}$ (Ponza) (For interpretation of the references color in this figure legend, the reader is referred to the Web version of this article).

within the earlier phases of the stress response, after which further compensative and/or adaptive processes may be activated (Franzellitti et al., 2010; Franzellitti and Fabbri, 2005; Maor-Landaw et al., 2014; Morris et al., 2013; Rosic et al., 2014a).

After acclimatization, 12 nubbins/polyps for each species were collected to account for differences in animal physiological status at the onset of the experimental exposure to thermal stress, thus representing the control condition of the experiment ( 2 nubbins/polyps were pooled together to give 6 samples per species; $\mathrm{N}=6$ ). The remaining samples were divided in different transparent glass beakers, to facilitate their manipulation during the experiments, and transferred to an experimental tank where the water temperature was raised to $32^{\circ} \mathrm{C}$. The samples were maintained at $32{ }^{\circ} \mathrm{C}$ for $2 \mathrm{~h}$, and then allowed to recover for $0-, 2$-, or 24-h post-stress periods at the acclimatization temperature $\left(17^{\circ} \mathrm{C}\right)$ (Fig. 3). At each time-point 6 nubbins/polyp per species were

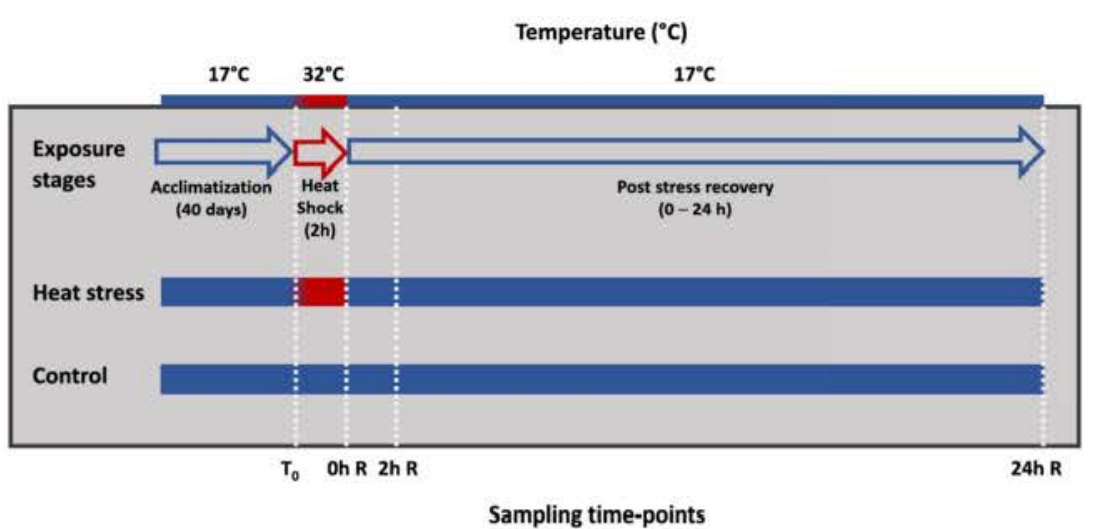

sampled, randomly pooled into 3 samples (2 nubbins/polyps for each sample), immediately immersed in RNA later solution (Sigma Aldrich, Milan, Italy), and stored at $-80^{\circ} \mathrm{C}$ for subsequent procedures (see below). Thermal stress experiments were settled to allow $0 \mathrm{~h}$ and $24 \mathrm{~h}$ post-stress recovery samplings at the same time at which the field samplings were performed.

\subsection{RNA extraction and CDNA preparation}

Nubbin/polyp pools were homogenized in a suitable volume of the TRI Reagent (Sigma Aldrich, Milan, Italy) according to Barshis et al. (2013). Total RNA was further extracted using the DirectZol kit (Zymo Research, Freiburg, Germany) according to the manufacturers' protocol. DNAase I treatment was performed within the RNA extraction procedures according to the manufacturers' instructions (Zymo Research,

Fig. 3. Scheme of the experimental design for the coral heat shock exposure. $T_{0}$ : time zero of the heat stress exposure, before the onset of the temperature challenge in the heat stress treatment. Sampling timepoints refer to the recovery periods (R) post-stress (For interpretation of the reference color in this figure legend, the reader is referred to the Web version of this article). 
Freiburg, Germany). RNA concentration and quality were confirmed using the Qubit system with the Qubit RNA assay kit (Thermo Scientific, Milan, Italy) and electrophoresis using a $1.2 \%$ agarose gel under denaturing conditions. RNA integrity was evaluated based on the presence of clear $28 \mathrm{~S}$ and $18 \mathrm{~S}$ ribosomal RNA bands in the electrophoresis, and by confirming that $28 \mathrm{~S}$ band intensity was at least double that of 18S. A further qualitative analysis was performed by measuring the UV absorbance spectra of the samples $(\lambda=200-340 \mathrm{~nm})$. Absorbances (A) at 260,230 , and $280 \mathrm{~nm}$ were used to calculate the ratio $A_{260} / A_{280}$ addressing the occurrence of protein contaminations (cut-off values $>1.8$ and $<2.0$ ), and the ratio $A_{260} / A_{230}$ addressing the occurrence of contaminants that may be present in the samples, such as guanidine thiocyanate, which is a component of the TRI Reagent (cutoff value $>1.7$ )

First strand cDNA for each sample was synthesized from $600 \mathrm{ng}$ total RNA using the iScript supermix following the manufacturer's protocol (Bio-Rad Laboratories, Milan, Italy).

\subsection{Cloning and sequencing}

The cDNAs corresponding to the coral $h s p 70$ mRNAs were amplified by a semi-nested PCR protocol using degenerated primers designed on conserved regions of a multiple alignment of homologous coral protein sequences retrieved from the GenBank and the Reefgenomics.org (Bhattacharya et al., 2016; Liew et al., 2016) databases (Table 1). The multiple alignment was done using the MEGA 6 software (Tamura et al., 2013) and a dataset of coral Hsp70 protein sequences reported by Poli et al. (2017). For each coral species, cDNA employed at this stage were synthetized from pooled heat-stressed coral total RNA samples ( $2 \mathrm{~h}$ at $32{ }^{\circ} \mathrm{C}+2 \mathrm{~h}$ of post-stress recovery). In the first PCR run, the primer pair CoHSP70F1 (5'-ATHGAYCTNGGNACNACNTA-3') and CoHSP7OR2 (5'-AGNACNSWNACRTCRAANGT- $3^{\prime}$ ) was used. In the second PCR run, products of the first PCR run were used as templates for the reaction with the CoHSP70F1 forward primer and the (internal) reverse primer CoHSP7OR1 (5'-NCCNGCRTCYTTNGTNGCYTG-3'). In both runs, PCR reactions were performed in a $25 \mu \mathrm{L}$ volume containing $3 \mu \mathrm{L}$ of cDNA template or $1 \mu \mathrm{L}$ of PCR product, $0.5 \mu \mathrm{M}$ each primer, $1.5 \mathrm{mM} \mathrm{MgCl}, 0.2 \mathrm{mM}$ each dNTP, and 0.5 units of RedTaq DNA polymerase (Sigma Aldrich, Milan, Italy). The thermal profile consisted of an initial denaturation step $\left(95^{\circ} \mathrm{C}, 10 \mathrm{~min}\right)$, followed by 38 cycles of denaturation $\left(94^{\circ} \mathrm{C}, 20 \mathrm{~s}\right)$, annealing $\left(52^{\circ} \mathrm{C}, 45 \mathrm{~s}\right)$ and extension $\left(72^{\circ} \mathrm{C}\right.$, $2 \mathrm{~min})$, and a final extension step $\left(72^{\circ} \mathrm{C}, 10 \mathrm{~min}\right)$. PCR products were separated on a $2.5 \%$ wide range agarose gel (Sigma Aldrich, Milan, Italy) using TBE buffer ( $1 \mathrm{M}$ Tris, $0.9 \mathrm{M}$ boric acid, and $1 \mathrm{mM}$ EDTA) and stained with the GelRed staining solution (Biotium, VWR International, Milan, Italy). Gels were analyzed with the Gel Doc ${ }^{\mathrm{Tx}}$ EZ System and the ImageLab software (Bio-Rad Laboratories, Milan, Italy). PCR products of the expected size were cloned into a PSC-A plasmid vector (Agilent, Milan, Italy) using the StrataClone PCR cloning kit (Agilent, Milan, Italy). No PCR product was detected from negative controls (reactions without reverse transcriptase added). The screening of clones was performed through EcoRI digestion of plasmid DNA, after plasmid extraction with the GenElute plasmid miniprep kit (Sigma Aldrich, Milan, Italy). Sequencing of both strands of the plasmid DNA from positive clones was performed by Sanger sequencing (BMR Genomics, Padoa, Italy). A dataset of available coral hsp70 nucleotide sequences was built using the corresponding protein sequence dataset reported by
Poli et al. (2017). The obtained nucleotide sequences were then aligned and analyzed against this dataset using the MEGA 6 program package (Tamura et al., 2013) to test the degree of sequence identity with other coral hsc70 and hsp70 genes.

\section{4. $q P C R$ assays}

Levels of $h s p 70$ transcripts was assayed by quantitative Real Time Polymerase Chain Reaction (qPCR) assays and using a protocol for the absolute quantification of the target transcripts. This approach was chosen to overcome the challenges in identifying stably expressed reference transcripts, which is a demanding issue in relative quantification studies (Bustin et al., 2013). Reliable reference transcripts are reported only for model tropical corals including Acropora and Pocillopora species (Oshiro et al., 2013; Overmans et al., 2018; Pagarigan and Takabayashi, 2008; Rosic et al., 2014a; van de Water et al., 2015). There is poor or no genomic/transcriptomic data for the species considered in this study, making it difficult to select and statistically validate any choice of best-performing reference transcripts (Balbi et al., 2016; Franzellitti et al., 2015; Rosic et al., 2014a).

A universal hsp70 primer pair was designed with the Primer Express software (Life Technologies, Milan, Italy) using nucleotide sequences obtained in this study (Table 1) and exhibiting low sequence homology to hsp70 from Symbiodinium clade A and C to avoid non-target amplification. $\mathrm{qPCR}$ standards for the target transcript were prepared by serial dilution of the linearized plasmid DNAs containing the specific transcripts to obtain a standard curve of $\mathrm{C}_{\mathrm{T}}$ values $v$ s the logarithmic DNA amount. $R^{2}$ values for all standard curves were $>0.99$. Absolute mRNA abundance was calculated from the standard curves and plotted as copy number $\mathrm{ng}^{-1}$ RNA (mean \pm SEM). Reactions were performed in a final volume of $10 \mu \mathrm{L}$ containing $5 \mu \mathrm{L}$ iTaq Universal SYBR Green Supermix with ROX (Bio-Rad Laboratories, Milan, Italy), $2 \mu \mathrm{L}$ diluted cDNA or plasmid DNA, and $0.2 \mu \mathrm{M}$ specific primers. A control lacking the DNA template (no-template) and a minus-reverse transcriptase (noRT) control were included in the qPCR analysis to ensure the specificity of the amplification.

Technical replicates were performed both within each run/plate (samples in duplicate, qPCR standards in triplicate) and between different runs/plates (standards and samples replicated on different plates). Equal loadings within each qPCR reaction were ensured by checking the amounts of each standard and cDNA sample using the Qubit system with Qubit ${ }^{\circ}$ dsDNA HS (High Sensitivity) assay kit (Thermo Scientific, Milan, Italy).

Amplification was detected with a StepOne real time PCR system (Life Technologies, Milan, Italy) using a standard "fast mode" thermal protocol. For each target mRNA, melting curves, gel pictures, and sequences of PCR products were analyzed to verify the specificity of the amplified products. PCR products for each species were cloned and sequenced. About 10 positive clones for each PCR product were sequenced that confirmed that they were identical to the respective nucleotide sequences originally employed for designing the selected primer pairs ( $L$. pruvoti sequences showed a mean $80 \%$ homology with sequences from other 4 selected species). Although potential off-target amplification of Symbiodinium transcripts cannot be completely ruled out, the low sequence homology to Symbiodnium hsp70 of the employed primer pair in combination with the melting curve analyses confirmed that the employed qPCRs mostly account for changes in mRNA

Table 1

Parameters of primers employed in the real-time qPCR assays.

\begin{tabular}{lllll}
\hline Primer name & Sequence $5^{\prime}-3^{\prime}$ & Amplicon size (bp) & Tm ( $\left.{ }^{\circ} \mathrm{C}\right)$ & Amplification efficiency" $(\%)$ \\
\hline MC_HSPOF & CTTTCCTTCCGAGATAGTCTTCAG & 107 & 62 & Samples: $109.8 \pm 10.9$ \\
MC_HSP7OR & TCGCGTACAGGTTGGTAAAG & & 62 & Standards: $108.3 \pm 9.6$ \\
\hline
\end{tabular}

a Amplification efficiencies for samples and standards are reported as mean \pm SD. Tm: melting temperature. 


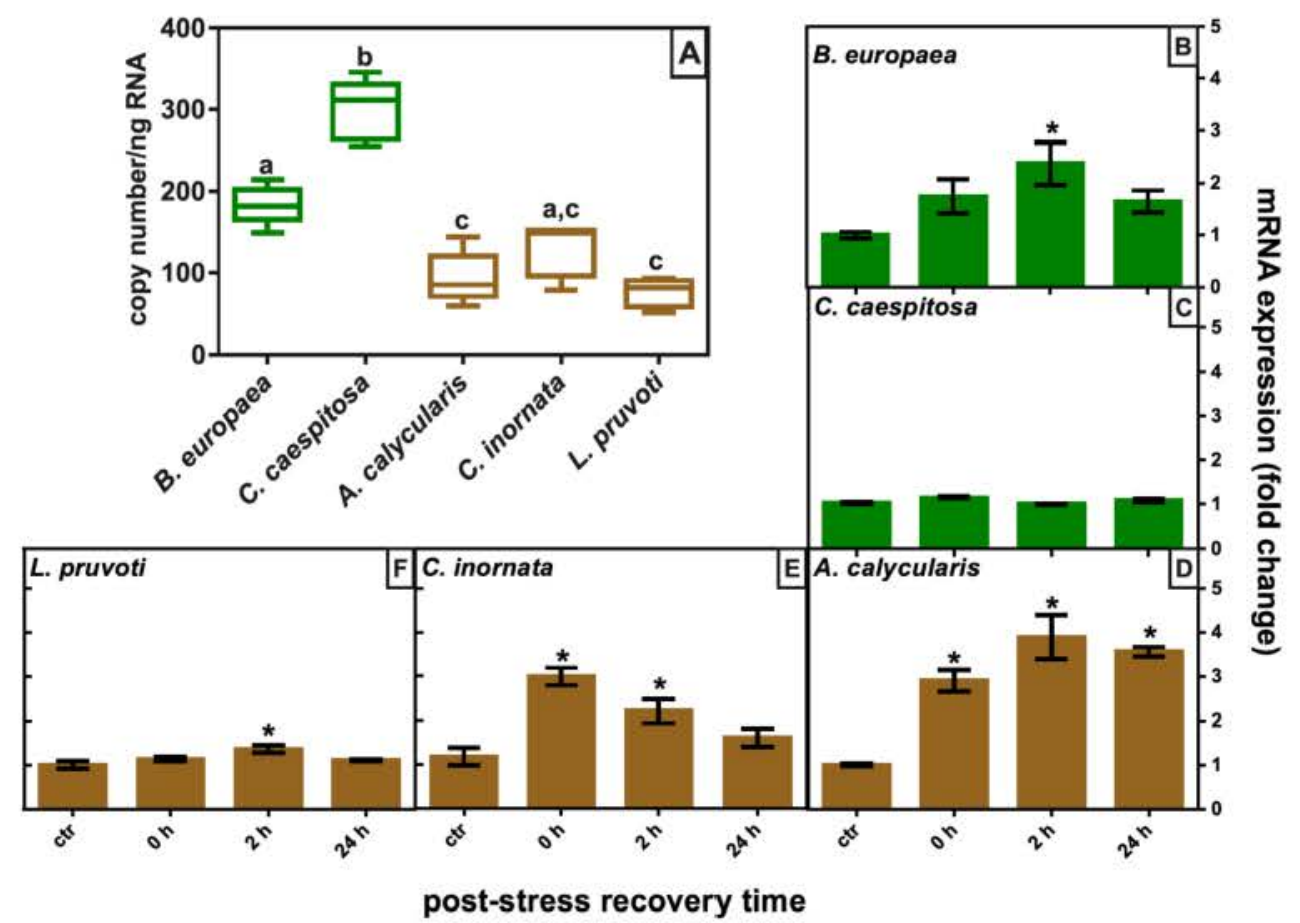

Fig. 4. Expression of hsp70 in Mediterranean shallow-water corals. (A) In situ hsp7o baseline expression in B. europaea, A. calycularis, C. inornata, C. caespitosa, and L. pruvoti. Box-and-whisker plots represent median, upper and lower quartiles $(\mathrm{N}=6)$ of $h s p 70$ copy number normalized over nanograms of total RNA employed in each PCR reaction. Different letters indicate statistical differences (P $<0.05$, Mann-Whytney $U$ test). (B-F) Expression of $h s p 70$ following an acute heat shock treatment $\left(2 \mathrm{~h}\right.$ at $\left.32^{\circ} \mathrm{C}\right)$ and several post-stress recovery periods $(0-24 \mathrm{~h})$ at $17^{\circ} \mathrm{C}$. Levels of $h s p 70$ are expressed as the relative variation (fold change) to controls (means \pm SEMs; $\mathrm{N}=3$ ). ${ }^{*} \mathrm{P}<0.05$ vs ctr (Mann-Whytney $U$ test). Species in green $=B$. europaea and $C$. caespitosa (zooxanthellate); species in brown $=A$. calycularis, $C$. inornata, and $L$. pruvoti (azooxanthellate) (For interpretation of the references to color in this figure legend, the reader is referred to the Web version of this article).

expression profiles of the coral species.

The amplification efficiency was calculated using a dilution series of samples cDNAs or of the linearized plasmid DNAs for the qPCR stan dards (Table 1). PCR efficiencies of the standards were not significantly different from those of the samples ( $P>0.05$, Mann-Whitney $U$ test) A standard curve was included in every PCR run. Consistency of technical replicates within each run was checked as a default operation by the StepOne software (standard deviations between replicates $<0.5$ ) Consistency of data between different runs was assured by analyzing reproducibility of $\mathrm{C}_{\mathrm{T}}$ values obtained from $\mathrm{QPCR}$ standards or randomly selected samples from any experimental condition ( $P>0.05$, MannWhitney $U$ test). Consistency of parameters of standard curves belonging to different runs was also assessed ( $\mathrm{P}>0.05$, Mann-Whitney $U$ test).

\subsection{Statistical analysis}

Univariate comparisons of $\mathrm{qPCR}$ data from in situ baseline evaluations and heat stress experiments were performed using the non-parametric one-way ANOVA (Kruskal-Wallis test) followed by the MannWhitney $U$ test $(\mathrm{P}<0.05)$, after deviations from parametric ANOVA assumptions were verified (Normality: Shapiro-Wilk's test; equal variance: Bartlett's test). Data analyses were performed using GraphPad Prism 6 software (GraphPad Inc.). Permutation multivariate analysis of variance (PERMANOVA) using the PERMANOVA + add-on in PRIMER v6 (Anderson et al., 2008) was performed on in situ hsp70 baseline expressions. Log-transformed hsp70 copy number variations were used to calculate similarity matrices based on the Euclidean distance (999 permutations). Factors considered were "growth mode" and "trophic strategy", that were used to calculate similarity matrices based on the
Euclidean distance (Anderson et al., 2008). An ordination analysis (carried out by Principal Coordinates, PCO) and data clustering using the PRIMER v6 software was performed on data from in situ hsp70 baseline levels in the selected coral species and pattern of $h s p 70$ overexpressions following heat stress. Log-transformed $h s p 70$ levels under in situ baseline conditions and $h s p 70$ induction across the post heat-stress recovery period (expressed as the calculated AUC, Area Under the Curve of the hsp70 transcriptional profiles for each species; Fig. S1 and Table S1, Supplemental material) were employed to calculate similarity matrices based on the Euclidean distance ( 999 permutations).

\section{Results}

\subsection{Sequencing of hsp70 cDNAs}

Using degenerated primers and a semi-nested PCR approach, sequences for partial hsp70 cDNAs from B. europaea (15), A. calycularis (17), C. inornata (11), and C. caespitose (9) were obtained. Positive clones included a partial ORF of about $450 \mathrm{bp}$ corresponding to the central fragment of the hsp70 coding region. Representatives of HSP70 sequences have been submitted to the GenBank database (A. calycularis: MH644814; B. europaea: MH618777; C. caespitosa: MH644815; C. inornata: MH618776). The sequences were aligned together with a dataset of coral hsp70 nucleotide sequences retrieved from GenBank and the Reefgenomics.org databases [the complete dataset corresponds to that reported by Poli et al. (2017) for related protein sequences]. Sequences of hsp70 for the analyzed species shared a major sequence identity (about $62 \%$ ) with hsp70s from members of the Porites family, while only an average $30 \%$ sequence identity with the available constitutive Scleractinian hsc70s. Amongst the selected Mediterranean 
Table 2

PERMANOVA results on basal $h s p 70$ expression in the selected Mediterranean corals under field conditions ( 998 permutations).

\begin{tabular}{llll}
\hline Source & df & Pseudo-F & P(perm) \\
\hline Growth mode & 1 & 3.622 & 0.069 \\
Trophic strategy & 1 & 98.653 & 0.001 \\
Growth mode x Trophic strategy & 1 & 11.935 & 0.003 \\
\hline
\end{tabular}

df: degree of freedom; Pseudo-F: F value by permutation (Anderson et al, 2008); P (perm): probability of pseudo-F.

corals, B. europaea and A. calycularis showed the highest pairwise sequence identity score (about $71 \%$ ), while the lowest score (about $53 \%$ ) was between $B$. europaea and $C$. inornata.

\subsection{Between-species differences of in situ hsp70 baseline expression levels}

Expression of hsp70 transcript was assessed in B. europaea, A. caly cularis, C. inornata, C. caespitosa, and L. pruvoti using an absolute quantitative real-time PCR assay (Fig, 4A). Results showed that the hsp70 transcripts were expressed in all samples of each species. The zooxanthellate species B. europaea and C. caespitosa displayed significantly higher in situ hsp70 levels compared to the azooxanthellae species. The only exception was represented by the azooxanthellate $C$. inornata, which showed in situ hsp70 baseline levels similar to those of B. europaea (Fig. 4A). PERMANOVA analyses of hsp70 expression revealed a significant interaction of the factors "trophic strategy" and "growth mode" (Table 2). Pairwise comparisons by permutation t-tests showed significantly higher in situ hsp70 baseline expression levels of the colonial morphotype within zooxanthellate species (Fig. 4A), while no significant differences within azooxanthellate corals were found (Table 3).

\subsection{Transcriptional responses and inter-species differences of the hsp70 expression profiles under a heat shock treatment}

Changes of hsp70 expression levels were evaluated following an acute heat shock $\left(2 \mathrm{~h}\right.$ at $\left.32^{\circ} \mathrm{C}\right)$ and different periods of post-stress recovery $(0 \mathrm{~h}, 2 \mathrm{~h}, 24 \mathrm{~h})$ at the control temperature $\left(17^{\circ} \mathrm{C}\right)(\mathrm{Fig} .3)$. For each species, values were normalized against mRNA expression levels at the onset of the experimental exposure to thermal stress (control samples, ctr), achieved after a 40-days acclimation period to laboratory conditions (Fig. S2, Supplemental material).

Among zooxanthellate species, B. europaea showed significantly increased hsp70 expression at $2 \mathrm{~h}$ post-stress recovery (Fig. 4B), with levels decreasing thereafter, while $C$. caespitosa showed no significant variation of $h s p 70$ levels (Fig, 4C). Amongst azooxanthellate species, $A$ calycularis showed the highest $h s p 70$ fold-change increase, with levels being significantly higher than controls from $0 \mathrm{~h}$ post-stress recovery and reaching a 3.5-fold and 3-fold up-regulation at $2 \mathrm{~h}$ and $24 \mathrm{~h}$ poststress recovery, respectively (Fig. 4D). Levels of $h s p 70$ in C. inornata were significantly increased compared to controls at $0 \mathrm{~h}$ post-stress and recovered control values thereafter (Fig. 4E). L. pruvoti showed a small though significant hsp70 over-expression at $2 \mathrm{~h}$ post-stress recovery,

Table 3

Permutation t-tests through PERMANOVA pairwise comparisons for the effects of the factor "growth mode" on basal $h s p 70$ expression amongst zooxanthellate or azooxanthellate species.

\begin{tabular}{llll}
\hline $\begin{array}{l}\text { Pairwise comparisons (colonial vs } \\
\text { solitary polyp) }\end{array}$ & $\mathrm{t}$ & P(perm) & Unique permutations \\
\hline Azooxanthellate species & 1.02 & 0.299 & 747 \\
Zooxanthellate species & 5.55 & 0.002 & 747 \\
\hline
\end{tabular}

t: t-Statistics; $\mathrm{P}($ perm): probability of $\mathrm{t}$.

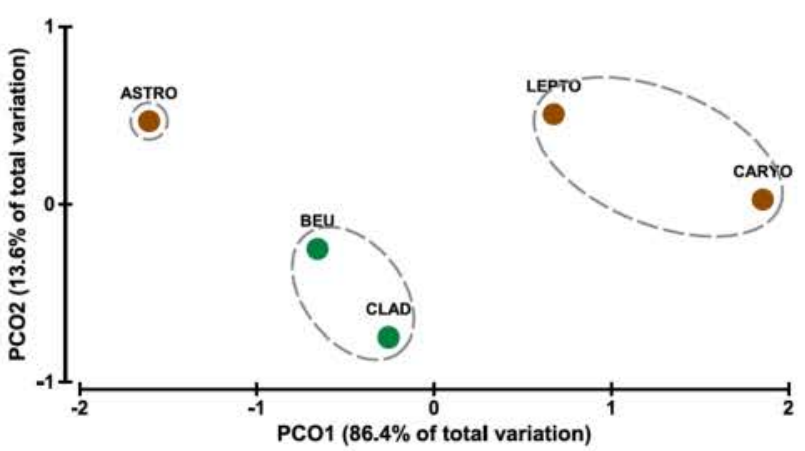

Fig. 5. Principal coordinates ordination (PCO) bi-plot of the hsp70 response with super-imposed cluster analysis (grey dotted lines) by condition (i.e., different morphotype and different symbiotic partnership) (Euclidean Distance resemblance matrix; 999 permutations). PCO and cluster analyses were performed on a resemblance matrix generated from both in situ hsp 70 baseline expression and $h s p 70$ induction across different periods of post heat-stress recovery (area under the curve, AUC, showing the hsp70 fold change variations across the post-stress recovery period; Fig. S1 and Table. S1, Supplemental material). Green circles indicate the zooxanthellate species, orange circles indicate azooxanthellate species. ASTRO: A. calycularis; BEU: B. europaea; CARYO: C. inornata; CLAD: C. caespitosa; LEPTO: L. pruvoti (For interpretation of the references to color in this figure legend, the reader is referred to the Web version of this article).

and no significant variations at 0 and $24 \mathrm{~h}$ post-stress recovery (Fig. 4F).

A PCO analysis was applied to determine whether the factors "growth mode" and "trophic strategy" could discriminate samples by means of variations of in situ hsp70 baseline expressions as well as of species-specific differences of hsp70 response in the post heat-stress recovery experiment (Fig. 5). The latter parameter was measured by assessing the area under the curve describing $h s p 70$ transcriptional profiles across the recovery period post-stress (Fig. S1 and Table. S1, Supplemental material). Two principal coordinates (PCO1 and PCO2) were observed to explain $100 \%$ of total variance $(86.4 \%$ and $13.6 \%$, respectively). The super-imposed data clustering showed that samples from zooxanthellate $B$. europaea and $C$. caespitosa formed one group with marked separation from the azooxanthellate species (Fig. 4). Amongst the azooxanthellate corals, A. calycularis showed separation from $C$. inornata and $L$. pruvoti, likely due to the remarkably different hsp70 transcriptional profile (i.e. higher AUC values) during the 24-h post stress recovery (Fig. 4).

\section{Discussion}

In this study, we explored whether five shallow-water coral species of the Mediterranean Sea with different growth modes (solitary vs colonial) and trophic strategies (zooxanthellate vs azooxanthellate) have differential transcriptional profiles of their $h s p 70$ expression in situ and in response to thermal stress. Notably, these species showed distinct susceptibilities towards temperature (Fig. 1).

Degenerated primers designed based on the multiple alignment of homologous hsp70 coral protein-coding nucleotide sequences allowed the identification of partial hsp70 sequences in B. europaea, A. calycularis, $C$. inornata, C. caespitosa. Sequence alignments and identity scores showed that these partial sequences encoded heat inducible HSP70s displaying a $60 \%-68 \%$ sequence identity with inducible HSP70s from Porites australiensis, while only about $30 \%$ sequence identity with the available constitutively expressed scleractinian hsc70s. These partial sequences were employed to design specific primer pairs to be used in absolute qPCR protocols. Validation by electrophoresis, cloning, and sequencing of $\mathrm{QPCR}$ products demonstrated that the same set of primers allowed $h s p 70$ transcriptional analysis in all the five Mediterranean coral species investigated in this study and detected no amplification of 
algal symbiont $h s p 70$ transcripts. Consequently, these primers were used to assess hsp70 expression across further Mediterranean coral species

Transcript levels of $h s p 70$ were evaluated immediately after coral sampling to account for differences in mRNA expression under in situ conditions and to assess baseline expression levels in the natural en vironment. Further, hsp70 expression was assessed in nubbins/polyps experimentally subjected to a short-term heat stress exposure $(2 \mathrm{~h}$ at $\left.32{ }^{\circ} \mathrm{C}\right)$ and after different periods of post-stress recovery $(0-24 \mathrm{~h}$ at $17^{\circ} \mathrm{C}$ ). Coral species with higher in situ hsp70 baseline levels had limited (B. europaea) or no evident (C. caespitosa) hsp70 induction by heat stress. This is a well-known phenomenon, common to several invertebrates inhabiting shallow-water environments (Franzellitti and Fabbri, 2005; Tomanek, 2010), and has been termed "constitutive gene frontloading" (Barshis et al., 2013). The occurrence of a minimal constitutive $h s p 70$ expression is likely part of the strategy loaded by these organisms to cope with frequently encountered environmental stress conditions (Fabbri et al., 2008; Morris et al., 2013). This strategy is thought to confer physiological resilience by means of faster reaction at the protein level during transient heat stress (Bay and Palumbi, 2017; Bellantuono et al., 2012; Ruiz-jones and Palumbi, 2017). Previous studies highlighted a frontloading behavior of $h s p 70$ transcripts through reciprocal transplanting of Acropora hyacintus nubbins between sites experiencing distinct temperature regimes (Barshis et al., 2013; Bay and Palumbi, 2017), or assessing the influence of depth-related basal expression profiles on $h s p 70$ induction in $P$. verrucosa (Poli et al., 2017). In agreement with these observations, in this study the most remarkable differences in the $h s p 70$ responses were observed between zooxanthellate and azooxanthellate species, suggesting that symbiosis may play an important role in modulating stress response capabilities of the coral hosts. Specifically, zooxanthellate corals showed higher in situ hsp70 baseline expression than the azooxanthellates, suggesting that this might be consequence of the symbiosis that is arguably highly susceptible to the effects of thermal stress. Furthermore, among zoox anthellate species, C. caespitosa showed higher in situ hsp70 baseline levels than B. europaea, and remarkably different post heat-stress transcriptional profiles were observed between these two species. Although composition of Symbiodinium clades hosted by the two species was not assessed in this study, previous reports on the Tyrrhenian Sea showed that either B. europaea or C. caespitosa harbored clade B2, while clade A was found only in B. europaea (Barbrook et al., 2006; Meron et al., 2012). Physiologically, the "temperate" clade A is thought to confer potential resistance to short-term increases in temperature (Rodolfo-Metalpa et al., 2006a). Therefore, this finding may explain the more effective $h s p 70$ induction by heat stress displayed by $B$. europaea. Besides the putative influence of symbiosis, peculiar life history traits and adaptive features of these species may have a role in determining their observed $h s p 70$ responses. Being sympatric species, B. europaea and $C$. caespitosa have a widely overlapping habitat distribution; hence, differences with regard to different environmental exposure do not serve as an explanation for the observed species-specific responses. We may hypothesize a relationship between stress responsiveness at the transcriptional level and colonial (C. caespitosa) vs solitary (B. europaea) coral morphotype. More generally, coral morphology is thought to influence flow regimes and thermal fluxes at the tissue-water interface (Jimenez et al., 2011; Nakamura and Van Woesik, 2001), tissue thickness and availability of resources (Loya et al., 2001), and to affect diversity and light-absorbing properties of the zooxanthellae symbionts (Enriquez et al., 2005; Yost et al., 2013). A recent study modeled the relationships between allometric scaling and rates of heating/cooling in coral microenvironments as a result of physical and geometric constraints on body size and shape, and showed that, under similar water flow and irradiance conditions, smaller corals are subjected to comparatively higher stress levels than bigger corals (Ong et al., 2017). Consequently, during the heat treatments the (smaller) solitary morphotype (B. europaea) investigated in this study may have experienced relatively higher heat fluxes at the water-polyp interface compared to the (bigger) colonial $C$. caespitosa, thus showing higher $h s p 70$ induction.

Cladocora caespitosa has been subjected to recurring mass bleaching and mortality events due to anomalous heat waves in different areas of the Mediterranean Sea (Jimenez et al., 2016; Kersting et al., 2013; Rubio-Portillo et al., 2016). These events may have contributed to shaping physiological outputs of this species in response to temperature, likely diminishing the natural capacity of the species to recover (Kersting et al., 2013). The comparatively high(er) in situ hsp70 baseline levels displayed by $C$. caespitosa may render this species less responsive to additional stress(ors). Indeed, no further $h s p 70$ up-regulation during post-stress recovery was observed, suggesting a limited ability of this species to further adjust its physiology to increasing temperatures. On the whole, both physiological (Rodolfo-Metalpa et al., 2006b, 2006a) and transcriptional (present study) outcomes support the finding of $C$. caespitosa living close to its upper thermal tolerance limit within the Mediterranean Sea (Rodolfo-Metalpa et al., 2006b). Considering that $C$. caespitosa is listed as endangered by the IUCN (Otero et al., 2017), these findings may contribute to the growing body of knowledge on the vulnerability of this species towards projected sea temperature rise.

Although in situ hsp70 baseline expression was not significantly different amongst the azooxanthellate species, different temporal profiles were observed after heat shock exposure. Based on the magnitude of hsp70 induction in heat-shock experiments, the following ranking of heat sensitivity can be defined: $A$. calycularis $>C$. inornata $>$ L. pruvoti. This ranking agrees with the relative stress tolerances of the species predicted from variations of growth, reproduction, and population dynamics across environmental gradients (Caroselli et al., 2017, 2016a; 2016b) (Fig. 1). Leptosammia pruvoti appears the less sensitive amongst the azooxanthellate species investigated in this study, showing a very limited increase of hsp70 expression only at $2 \mathrm{~h}$ post-stress recovery. Indeed, this species showed unaffected physiological outputs along extended latitudinal thermal and solar irradiance gradients (Airi et al., 2017; Caroselli et al., 2012a, 2011; Goffredo et al., 2007). A. calycularis resulted the most sensitive azooxanthellate species, showing the highest hsp70 fold changes, in agreement with the relevant physiological effects of hypertermic stress observed in this species (Movilla et al., 2016; Prada et al., 2017). Compared to L. pruvoti, A. calycularis seems particularly sensitive to high summer temperatures, displaying a relevant increase in tissue mortality that probably made the corals more susceptible to the detrimental effects of further stress events (Prada et al., 2017). Notably, A. calycularis maintained significant hsp70 up-regulation up to $24 \mathrm{~h}$ post-stress recovery, which may suggest a slow reactivity or a partial temperature-dependent impairment of the cellular machinery at the basis of its heat stress response, as previously observed in the temperature-sensitive oyster Ostrea edulis exposed to near-lethal temperature increases under a similar exposure scheme (Piano et al., 2004).

\section{Conclusions}

Data reported in this study indicate that transcriptional responses of the hsp70 gene align with previously reported relative differences in stress susceptibility of the coral species investigated. Although variability in environment requirements is considered a pivotal factor in determining the degree of stress resilience in shallow-water species, our results suggest that trophic strategy and morphology may play an important role in shaping coral resilience and physiological plasticity, as previously hypothesized (Samorì et al., 2017; Seveso et al., 2018). Combining baseline hsp70 expression and heat stress induction allowed discriminating the potential of stress responses between zooxanthellate and azooxanthellate species, as well as, within the different trophic strategies, between colonial $v s$ solitary corals. Whether scientific evidences are calling into question the role of symbiosis as a buffer towards the adverse effects of environmental stressors (Ellison et al., 2017; Levin et al., 2016; Schwarz et al., 2008), the relevance of coral 
morphology in shaping holobiont response to environment variability is underestimated. In this light, results of this study let argue that bigger (colonial) morphotype may represent a winning physiological trait to promote stress tolerance and adaptation in a global warming scenario. Future studies incorporating further species should assess whether hsp70 expression may serve as a hallmark of coral trophic status and morphological constraints. Understanding these molecular processes can contribute to disclose the relevant physiological traits underpinning these coral tolerances to stress, and this will help us predicting the future of shallow-water corals under projected scenarios of anthropogenic global change.

\section{Competing interests}

No competing interests declared.

\section{Acknowledgements}

This work is part of the Master Degree Thesis in Marine Biology of D.C. The research was supported by the Italian Ministry of Research and University RFO2016 to S.F. and E.F., and by grant of the European Research Council under the European Union's Seventh Framework Programme (FP7/2007-2013)/ERC grant agreement n'8 [249930CoralWarm: Corals and global warming: the Mediterranean versus the Red Sea; www.CoralWarm.eu ] to V.A., E.C., F.P., G.F., and S.G..

\section{References}

Airi, V., Prantoni, S., Calegari, M., Lisini Baldi, V., Gizzi, F., Marchini, C., Levy, O., Falini, G., Dubinsky, Z, Goffredo, S., 2017. Reproductive output of a non-zooxanthellate temperate coral is unaffected by temperature along an extended latitudinal gradient. PLoS One 12, e0171051. hitps://doi.org/10.1371/journal.pone.0171051.

Altieri, A.H., Harrison, S.B., Seemann, J., Collin, R., Diaz, R.J., Knowiton, N., 2017. Tropical dead zones and mass mortalities on coral reefs. Proc. Natl. Acad. Sci. Unit. States Am. 114, 3660-3665. hitps://doi.org/10.1073/pnas.1621517114.

Anderson, M., Gorley, R, Clarke, K., 2008, PERMANOVA + for PRIMER: Guide to Software and Statistical Methods.

Balbi, T., Franzellitti, S., Fabbri, R., Montagna, M., Fabbri, E., Canesi, L., 2016. Impact of bisphenol A (BPA) on early embryo development in the marine mussel Mytilus galloprovincialis: effects on gene transcription. Environ. Pollut. 218, 996-1004. https:/, doi.org/10.1016/J,envpol.2016.08,050.

Barbrook, A.C., Visram, S., Douglas, A.E., Howe, C.J., 2006. Molecular diversity of dinoflagellate symbionts of Cnidaria: the psbA minicircle of Symbiodinium. Protist 157, 159-171. huttps://doi.org/10.1016/j.protis.2005.12.002.

Barshis, D.J., Ladner, J.T., Oliver, T.A., Seneca, F.O., Traylor-Knowles, N., Palumbi, S.R. 2013. Genomic basis for coral resilience to climate change. Proc. Natl. Acad. Sci. Unit. States Am. 110, 1387-1392, hups//doi,orz/10.1073/pnas. 1210224110.

Bay, R.A., Palumbi, S.R., 2017. Transeriptome predictors of coral survival and growth in a highly variable environment. Evol. Ecol. 7. 4794-4803. https://doi.org/10.1002/ ece 3.2685 .

Bellantuono, A.J., Granados-Cifuentes, C., Miller, D.J., Hoegh-Guldberg, O., RodriguezLanetty, M., 2012. Coral thermal tolerance: tuning gene expression to resist therma stress. PLoS One 7, e50685. https://doi.org/10.1371/journal.pone.0050685.

Bhattacharya, D., Agrawal, S., Aranda, M., Baumgarten, S., Belcaid, M., Drake, J.L., Erwin, D., Foret, S., Gates, R.D., Gruber, D.F., Kamel, B., Lesser, M.P., Levy, O., Liew Y.J., MacManes, M., Mass, T., Medina, M., Mehr, S., Meyer, E., Price, D.C., Putnam H.M., Qiu, H., Shinzato, C., Shoguchi, E., Stokes, A.J., Tambutté, S., Tchernov, D., Voolstra, C.R., Wagner, N., Walker, C.W., Weber, A.P., Weis, V., Zelzion, E., Zoccola, D., Falkowski, P.G., 2016. Comparative genomics explains the evolutionary success of reef-forming corals. Elife 5, 1-26, https://doi.org/10.7554/elife.13288.

Brown, T., Bourne, D., Rodriguez-Lanetty, M., 2013. Transcriptional activation of $\mathrm{c} 3$ and hsp70 as part of the immune response of Acropora millepora to bacterial challenges. PLoS One 8, e67246. https://doi.org/10.1371/journal.pone.0067246.

Bustin, S.A., Benes, V., Garson, J., Hellemans, J., Huggett, J., Kubista, M., Mueller, R., Nolan, T., Pfaff, M.W., Shipley, G., Wittwer, C.T., Schjerling, P., Day, P.J., Abreu, M. Aguado, B., Beaulieu, J.F., Beckers, A., Bogaert, S., Browne, J.A., Carrasco-Ramiro, F., Ceelen, L., Ciborowski, K., Cornillie, P., Coulon, S., Cuypers, A., De Brouwer, S., De Ceuninck, L., De Craene, J., De Naeyer, H., De Spiegelaere, W., Deckers, K., Dheedene, A., Durinck, K., Ferreira-Teixeira, M., Fieuw, A., Gallup, J.M., GonzaloFlores, S., Goossens, K., Heindryckx, F., Herring, E., Hoenicka, H., Icardi, L., Jaggi, R.,
Javad, F., Karampelias, M., Kibenge, F., Kibenge, M., Kumps, C., Lambertz, L., Lammens, T., Markey, A., Messiaen, P., Mets, E., Morais, S., Mudarra-Rubio, A., Nakiwala, J., Nelis, H., Olsvik, P.A., Pérez-Novo, C., Plusquin, M., Remans, T., Rihani, A., Rodrigues-Santos, P., Rondou, P., Sanders, R., Schmidt-Bleek, K., Skovgaard, K., Smeets, K., Tabera, L., Toegel, S., Van Acker, T., Van Den Broeck, W., Van Der Meulen, J., Van Gele, M., Van Peer, G., Van Poucke, M., Van Roy, N., Vergult, S. Wauman, J., Tshuikina-Wiklander, M., Willems, E., Zaccara, S., Zeka, F., Vandesompele, J., 2013. The need for transparency and good practices in the qPCR
. Vandesompele, J., 2013. The need for transparency and good practices in the qPCR
literature. Nat. Methods 10, 1063-1067. https//doi.org/10.1038/rmeth.2697.

Caroselli, E., Brambilla, V., Ricci, F., Mattioli, G., Levy, O., Falini, G., Dubinsky, Z, Goffredo, S., 2016a. Inferred calcification rate of a temperate azooxanthellate caryophylliid coral along a wide latitudinal gradient. Coral Reefs 35, 919-928. hitps:/, doi.org/10.1007/s00338-016-1422-3.

Caroselli, E., Falini, G., Goffredo, S., Dubinsky, Z., Levy, O., 2015a. Negative response of photosynthesis to natural and projected high seawater temperatures estimated by pulse amplitude modulation fluorometry in a temperate coral. Front. Physiol. 6, pulse amplitude modulation fluorometry in a tempera
$1-11$. hitps:/doi.org/10.3389/fphys.2015.00317.

Caroselli, E., Mattioli, G., Levy, O., Falini, G., Dubinsky, Z, Goffredo, S., 2012a. Inferred calcification rate of a Mediterranean azooxanthellate coral is uncoupled with sea surface temperature along an $8^{*}$ latitudinal gradient. Front. Zool. 9, 32. https://doi org/10.1186/1742.9994-9-32.

Caroselli, E., Nanni, V., Levy, O., Falini, G., Dubinsky, Z., Goffredo, S., 2015b. Latitudina! variations in biometry and population density of a mediterranean solitary coral. Limnol. Oceanogr. 60, 1356-1370. https://doi.arg/10.1002//no.10100.

Caroselli, E., Prada, F., Pasquini, L., Marzano, F.N., Zaccanti, F., Falini, G., Levy, O., Dubinsky, Z., Goffredo, S., 2011. Environmental implications of skeletal micro-density and porosity variation in two scleractinian corals. Zoology 114, 255-264. https://doi.org/10.1016/j.200L.2011.04.003.

Caroselli, E., Ricci, F., Brambilla, V., Marchini, C., Tortorelli, G., Airi, V., Mattioli, G., Levy, O., Falini, G., Dubinsky, Z., Goffredo, S., 2017. Growth, population dynamics, and reproductive output model of the non-zooxanthellate temperate solitary coral Caryophyllia inomata (Scleractinia, Caryophyllidae). Limnol. Oceanogr. 62 , 1111-1121. https://doi.org/10.1002/1no.10489.

Caroselli, E., Ricci, F., Brambilla, V., Mattioli, G., Levy, O., Falini, G., Dubinsky, Z., Goffredo, S., 2016b. Relationships between growth, population dynamics, and environmental parameters in the solitary non-zooxanthellate scleractinian coral vironmental parameters in the solitary non-zooxanthellate scleractinian coral
Caryophyllia inomata along a latitudinal gradient in the Mediterranean Sea. Coral Reefs 35, 507-519. https://doi.org/10.1007/s00338-015-1393-9.

Caroselli, E., Zaccanti, F., Mattioli, G., Falini, G., Levy, O., Dubinsky, Z., Goffredo, S., $2012 \mathrm{~b}$. Growth and demography of the solitary scleractinian coral Leptopsammia privoti along a sea surface temperature gradient in the Mediterranean sea. PLoS One 7. https//doi.org/10.1371/journal.pone.0037848.

Diffenbaugh, N.S., Pal, J.S., Giorgi, F., Gao, X., 2007. Heat stress intensification in the Mediterranean climate change hotspot. Geophys. Res. Lett. 34 L.11706. https://dol. org/10.1029/2007GL030000.

Dixon, G.B., Davies, S.W., Aglyamova, G.A., Meyer, E., Bay, L.K., Matz, M.V., 2015 Genomic determinants of coral heat tolerance across latitudes. Science 348, 1460-1462. https://doi.org/10.1017/CBO9781107415324.004.

Ellison, M.A., Ferrier, M.D., Carney, S.L., 2017. Salinity stress results in differential Hsp70 expression in the Exaiptasia pallida and Symbiodinium symbiosis. Mar. Environ. Res. 132, 63-67. hrtps://doi.org/10.1016//.marenvres.2017.10,006.

Enriquez, S., Méndez, E.R., Prieto, R.I., 2005, Multiple scattering on coral skeletons enhances light absorption by symbiotic algae. Limnol. Oceanogr. 50, 1025-1032. https://doi.org/10.4319/lo.2005.50.4.1025.

Fabbri, E., Valbonesi, P., Franzellitti, S., 2008. HSP expression in bivalves. Invertebr. Surviv. J. 5, 135-161.

Feder, M.E., Hofmann, G.E., 1999. Heat-shock proteins, molecular chaperones, and the stress response: evolutionary and ecological physiology. Annu. Rev. Physiol. 61, 243-282. https://doi.org/10.1146/annurev. physiol.61.1.243.

Franzellitti, S., Buratti, S., Donnini, F., Fabbri, E., 2010. Exposure of mussels to a polluted environment: insights into the stress syndrome development. Comp. Biochem. Physiol., C 152, 24-33. https://doi.org/10.1016/.cbpc.2010.02.010.

Franzellitti, S., Fabbri, E, 2005. Differential HSP70 gene expression in the Mediterranean mussel exposed to various stressors. Biochem. Biophys. Res. Commun. 336, 1157-1163. hitps://doi.org/10.1016/j.bbrc.2005.08.244.

Framzellitti, S., Kiwan, A., Valbonesi, P., Fabbri, E., 2015. Selection of best-performing reference gene products for investigating transcriptional regulation across silvering in the European eel (Anguilla anguilla). Sci. Rep. 5, 16966. https://doi.org/10.1038/ srep16966.

Gates, R.D., Edmunds, P.J., 1999. The physiological mechanisms of acclimatization in tropical reef corals. Am. Zool. 39, 30-43. https://doi.org/10.1093/icb/39.1.30,

Giorgi, F., Lionello, P., 2008. Climate change projections for the Mediterranean region. Global Planet. Change 63, 90-104. hitps://doi.org/10.1016/j.gloplacha. 2007.09. 005 .

Goffredo, S., Caroselli, E., Mattioli, G., 2009. Inferred level of calcification decreases along an increasing temperature gradient in a Mediterranean endemic coral. Limnol. Oceanogr. 54, 930-937. hitps://doi.org/10,4319/lo.2009.54.3.0930.

Goffredo, S., Caroselli, E., Mattioli, G., Pignotti, E., Zaccanti, F., 2008. Relationships between growth, population structure and sea surface temperature in the temperate solitary coral Balanophyllia europaea (Scleractinia, Dendrophylliidae). Coral Reefs 27, 623-632. https://doi.org/10.1007/s00338-008-0362-y.

Goffredo, S., Caroselli, E., Pignotti, E., Mattioli, G., Zaccanti, F., 2007. Variation in biometry and population density of solitary corals with solar radiation and sea surface temperature in the Mediterranean Sea. Mar. Biol. 152, 351-361. https://doi.org/10. 1007/500227-007-0695-2,

Gutner-Hoch, E., Waldman Ben-Asher, H., Yam, R., Shemesh, A., Levy, O., 2017. 
Identifying genes and regulatory pathways associated with the scleractinian cora calcification process. PeerJ 5 e3590. https://doi.org/10.7717/peerj.3590.

Hartl, F.U., Bracher, A., Hayer-Hartl, M., 2011. Molecular chaperones in protein foldin and proteostasis. Nature 475, 324-332. https://doi.org/10.1038/nature10317.

Hoegh-Guldberg, O., Mumby, P.J., Hooten, A.J., Steneck, R.S., Greenfield, P., Gomez, E., Harvell, C.D., Sale, P.F., Edwards, A.J., Caldeira, K., Knowlton, N., Eakin, C.M., Iglesias-Prieto, R., Muthiga, N., Bradbury, R.H., Dubi, A., Hatziolos, M.E., 2007. Coral reefs under rapid climate change and ocean acidification. Science 318, 1737-1742 reefs under rapid climate change and ocea

Hughes, T.P., Anderson, K.D., Connolly, S.R., Heron, S.F., Kerry, J.T., Lough, J.M., Bairi, A.H., Baum, J.K., Berumen, M.L., Bridge, T.C., Claar, D.C., Eakin, C.M., Gilmour, J.P. Graham, N.A.J., Harrison, H., Hobbs, J.P.A., Hoey, A.S., Hoogenboom, M., Lowe, R.J., McCulloch, M.T., Pandolfi, J.M., Pratchett, M., Schoepf, V., Torda, G., Wilson, S.K., 2018. Spatial and temporal patterns of mass bleaching of corals in the Anthropocene. Science 359, 80 LP-83.

Jimenez, C., Hadjioannou, L., Petrou, A., Nikolaidis, A., Evriviadou, M., Lange, M.A. 2016. Mortality of the scleractinian coral Cladocora caespitosa during a warming event in the Levantine Sea (Cyprus). Reg. Environ. Change 16, 1963-1973. https:// doi.org/10.1007/s10113-014-0729-2.

Jimenez, I.M., Kühl, M., Larkum, A.W.D., Ralph, P.J., 2011. Effects of flow and colony morphology on the thermal boundary layer of corals. J. R. Soc. Interface 8 , 1785-1795. https://doi.org/10.1098/rsif.2011.0144.

Jovanović, B., Guzmán, H.M., 2014. Effects of titanium dioxide $\left(\mathrm{TiO}_{2}\right)$ nanoparticles on caribbean reef-building coral (Montastraea faveolata). Environ. Toxicol. Chem. 33, 1346-1353. https://doi,org/10.1002/etc.2560.

Kersting, D.K., Bensoussan, N., Linares, C., 2013. Long-term responses of the endemic reef-builder Cladocora caespitosa to Mediterranean warming. PLoS One 8. https: doi.org/10.1371/journal.pone.0070820.

Kvitt, H., Rosenfeld, H., Tchernov, D., 2016. The regulation of thermal stress induced apoptosis in corals reveals high similarities in gene expression and function to highe animals. Sci. Rep. 6, 1-8. https://doi.org/10.1038/srep30359.

Levin, R.A., Beltran, V.H., Hill, R., Kjelleberg, S., McDougald, D., Steinberg, P.D., Oppen, M.J.H. van, 2016. Sex, scavengers, and chaperones: transcriptome secrets of divergent Symbiodinium thermal tolerances. Mol. Biol. Evol. 33, 2201-2215. https:// doi.org/10.1093/molbev/msw119.

Levy, O., Kaniewska, P., Alon, S., Eisenberg, E., Karako-Lampert, S., Bay, L.K., Reef, R. Rodriguez-Lanetty, M., Miller, D.J., Hoegh-Guldberg, O., 2011. Complex diel cycles of gene expression in coral-algal symbiosis. Science 331,175 . https://doi.org/10. 1126/science.1196419.

Liew, Y.J., Aranda, M., Voolstra, C.R., 2016. Reefgenomics.Org - a repository for marine genomics data. Database 2016. https://doi.org/10.1093/database/baw152

Louis, Y.D., Bhagooli, R., Kenkel, C.D., Baker, A.C., Dyall, S.D., 2017. Gene expression biomarkers of heat stress in scleractinian corals: promises and limitations. Comp Biochem. Physiol., C 191, 63-77. https://doi.org/10.1016/j.cbpc.2016.08.007.

Loya, Y., Sakai, K., Nakano, Y., Woesik, R. Van, 2001. Coral bleaching: the winners and the losers. Ecol. Lett. 4, 122-131. https://doi.org/10.1046/j.1461-0248.2001. 00203.x.

Maor-Landaw, K., Karako-Lampert, S., Ben-Asher, H.W., Goffredo, S., Falini, G., Dubinsky, Z., Levy, O., 2014. Gene expression profiles during short-term heat stres in the red sea coral Stylophora pistillata. Global Change Biol. 20, 3026-3035. https:// doi.org/10.1111/gcb.12592

Maor-Landaw, K., Waldman Ben-Asher, H., Karako-Lampert, S., Salmon-Divon, M., Prada, F., Caroselli, E., Goffredo, S., Falini, G., Dubinsky, Z., Levy, O., 2017. Mediterranea versus Red Sea corals facing climate change, a transcriptome analysis. Sci. Rep. 7, 42405. https://doi.org/10.1038/srep42405.

Marshall, P.A., Baird, A.H., 2000. Bleaching of corals on the Great Barrier Reef: differential susceptibilities among taxa. Coral Reefs 19, 155-163. https://doi.org/10. $1007 / 5003380000086$

Meron, D., Rodolfo-Metalpa, R., Cunning, R., Baker, A.C., Fine, M., Banin, E., 2012. Changes in coral microbial communities in response to a natural pH gradient. ISME $\mathrm{J}$. 6, 1775-1785. https://doi.org/10.1038/ismej.2012.19.

Morris, J.P., Thatje, S., Hauton, C., 2013. The use of stress-70 proteins in physiology: a reappraisal. Mol. Ecol. 22, 1494-1502, https://doi.org/10.1111/mec.12216.

Movilla, J., Calvo, E., Coma, R., Serrano, E., López-Sanz, À., Pelejero, C., 2016. Annual response of two Mediterranean azooxanthellate temperate corals to low-pH and hightemperature conditions. Mar. Biol. 163, 1-14. https://doi.org/10.1007/s00227-016 2908-9.

Moya, A., Huisman, L., Forêt, S., Gattuso, J.-P., Hayward, D.C., Ball, E.E., Miller, D.J., 2015. Rapid acclimation of juvenile corals to $\mathrm{CO}_{2}$-mediated acidification by upregulation of heat shock protein and Bcl-2 genes. Mol. Ecol. 24, 438-452. hittps://dol. org/10.1111/mec.13021.

Nakamura, T., Van Woesik, R., 2001. Water-flow rates and passive diffusion partially explain differential survival of corals during the 1998 bleaching event. Mar. Ecol. Prog. Ser. 212, 301-304. https;/doi.org/10.3354/meps212301.

Oliver, T.A., Palumbi, S.R., 2011. Do fluctuating temperature environments elevate cora thermal tolerance? Coral Reefs 30, 429-440. https://doi.org/10.1007/500338-0110721-y.

Ong, R.H., King, A.J.C., Kaandorp, J.A., Mullins, B.J., Caley, M.J., 2017. The effect of allometric scaling in coral thermal microenvironments. PLoS One 12, 1-27. https: doi.org/10.1371/journal.pone.0184214.

Oshiro, Y., Kinjo, K., Nakasone, K., 2013. Validation of internal reference genes for gene expression analysis in Montipora digitata, Pocillopora damicornis and Acropora nasute by quantitative real-time PCR. Galaxea. J. Coral Reef Stud. 15, 1-11,

Otero, M. del M., Numa, C, Bo, M. Orejas, C., Garrabou, J, Cerrano, C, Kružic, P. Antoniadou, C., Aguilar, R., Kipson, S., Linares, C., Terrón-Sigler, A., Brossard, J., Kersting, D., Casado-Amezúa, P., Garcia, S., Goffredo, S., Ocaña, O., Caroselli, E.,
Maldonado, M., Bavestrello, G., Cattaneo-Vietti, R., Ozalp, B., 2017. Overview of the Conservation Status of Mediterranean Anthozoa | IUCN Library System. Gland, Malaga, Spain.

Overmans, S., Nordborg, M., Díaz-Rúa, R., Brinkman, D.L., Negri, A.P., Agustí, S., 2018. Phototoxic effects of PAH and UVA exposure on molecular responses and developmental success in coral larvae. Aquat. Toxicol. 198, 165-174. https://doi.org/10, 1016/J.AQUATOX.2018.03.008.

Pagarigan, L. Takabayashi, M. 2008. Reference gene selection for qRT.PCR analysis of the Hawaiian coral Pocillopora meandrina subjected to elevated levels of temperature and nutrient. In: Proc 11th Int Coral Reef Symp. pp. 7-11.

Palumbi, S.R., Barshis, D.J., Bay, R.A., 2014. Mechanisms of reef coral resistance to future climate change. Science 344, 895-898. https://doi.org/10.1126/science.1251336.

Parmesan, C., 2006. Ecological and evolutionary responses to recent climate change Annu. Rev. Ecol. Evol. Syst. 37, 637-669. https://doi.org/10.1146/annurev.ecolsys. 37.091305.110100

Piano, A., Franzellitti, S., Tinti, F., Fabbri, E., 2005. Sequencing and expression pattern of inducible heat shock gene products in the European flat oyster, Ostrea edulis. Gene 361, 119-126. https://doi.org/10.1016/j.gene.2005.06.034.

Piano, A., Valbonesi, P., Fabbri, E., 2004. Expression of cytoprotective proteins, heat shock protein 70 and metallothioneins, in tissues of Ostrea edulis exposed to heat and heavy metals. Cell Stress Chaperones 9, 134-142. https://doi.org/10.1379/483.1.

Poli, D., Fabbri, E., Goffredo, S., Airi, V., Franzellitti, S., 2017. Physiological plasticity related to zonation affects hsp70 expression in the reef-building coral Pocillopora verrucosa. PLoS One 12, e0171456. https://doi.org/10.1371/journal.pone.0171456.

Prada, F., Caroselli, E., Mengoli, S., Brizi, L., Fantazzini, P., Capaccioni, B., Pasquini, L., Fabricius, K.E., Dubinsky, Z., Falini, G., Goffredo, S., 2017. Ocean warming and acidification synergistically increase coral mortality. Sci. Rep. 7, 40842. https://dol. org/10.1038/srep40842

Richter, K., Haslbeck, M., Buchner, J., 2010. The heat shock response: life on the verge of death. Mol. Cell 40, 253-266. hitts://doi.org/10.1016/j.molcel.2010.10.006.

Rodolfo-Metalpa, R., Richard, C., Allemand, D., Bianchi, C.N., Morri, C., Ferrier-Pagès, C., 2006a. Response of zooxanthellae in symbiosis with the Mediterranean corals Cladocora caespitosa and Oculina patagonica to elevated temperatures. Mar. Biol. 150, 45-55. https://doi.org/10.1007/s00227-006-0329-x,

Rodolfo-Metalpa, R., Richard, C., Allemand, D., Ferrier-Pagès, C., 2006b. Growth and photosynthesis of two Mediterranean corals, Cladocora caespitosa and Oculina patogonica, under normal and elevated temperatures. J. Exp. Biol. 209, 4546-4556. https://doi.org/10.1242/jeb.02550.

Rosic, N., Kaniewska, P., Chan, C.-K.K., Ling, E.Y.S., Edwards, D., Dove, S., HoeghGuldberg, O., 2014a. Early transcriptional changes in the reef-building coral Acropora aspera in response to thermal and nutrient stress. BMC Genom. 15, 1052. https://doi. org/10.1186/1471-2164-15-1052.

Rosic, N., Ling, E.Y.S., Chan, C.-K.K., Lee, H.C., Kaniewska, P., Edwards, D., Dove, S. Hoegh-Guldberg, O., 2014b. Unfolding the secrets of coral-algal symbiosis. ISME J. 9, 1-13. https://doi.org/10.1038/ismej.2014.182.

Rubio-Portillo, E., Izquierdo-Muñoz, A., Gago, J.F., Rosselló-Mora, R., Antón, J., RamosEsplá, A.A., 2016. Effects of the 2015 heat wave on benthic invertebrates in the Tabarca Marine Protected Area (southeast Spain). Mar. Environ. Res. 122, 135-142. https://doi.org/10.1016/j.marenvres.2016.10.004.

Ruiz-jones, L.J., Palumbi, S.R., 2017. Tidal heat pulses on a reef trigger a fine-tuned transcriptional response in corals to maintain homeostasis. Sci. Adv. 3, 1-10. https:// doi.org/10.1126/sciadv, 1601298 .

Samori, C., Caroselli, E., Prada, F., Reggi, M., Fermani, S., Dubinsky, Z., Goffredo, S., Falini, G., 2017. Ecological relevance of skeletal fatty acid concentration and composition in Mediterranean scleractinian corals, Sci. Rep. 7, 1929, https://doi.org/10. 1038/s41598-017-02034-2

Schwarz, J.A., Brokstein, P.B., Voolstra, C., Terry, A.Y., Miller, D.J., Szmant, A.M., Coffroth, M.A., Medina, M., 2008. Coral life history and symbiosis: functional genomic resources for two reef building Caribbean corals, Acropora palmata and Montastraea faveolata. BMC Genom. 9, 97. https://doi.org/10.1186/1471-2164-9-97.

Seneca, F.O., Palumbi, S.R., 2015. The role of transcriptome resilience in resistance of corals to bleaching. Mol. Ecol. 24, 1467-1484, hitps:/dot.org/10.1111/mec.13125.

Seveso, D., Montano, S., Maggioni, D., Pedretti, F., Orlandi, I., Galli, P., Vai, M., 2018. Diel modulation of $\mathrm{Hsp} 70$ and $\mathrm{Hsp60}$ in corals living in a shallow reef. Coral Reefs. https://doi.org/10.1007/s00338-018-1703-0 in press.

Seveso, D., Montano, S., Reggente, M.A.L., Maggioni, D., Orlandi, L., Galli, P., Vai, M. 2016. The cellular stress response of the scleractinian coral Goniopora columna during the progression of the black band disease. Cell Stress Chaperones 225-236. https:/ doi.org/10.1007/s12192-016-0756-7.

Seveso, D., Montano, S., Strona, G., Orlandi, I., Galli, P., Vai, M., 2014. The susceptibility of corals to thermal stress by analyzing Hsp60 expression. Mar. Environ. Res. 99, 69-75. https://doi.org/10.1016/j.marenvres.2014.06.008.

Shaltout, M., Omstedt, A., 2014. Recent sea surface temperature trends and future scenarios for the Mediterranean Sea. Oceanologia 56, 411-443. https://dol.org/10. 5697/oc.56-3.411.

Somero, G.N., 2012. The physiology of global change: linking patterns to mechanisms. Annu. Rev. Mar. Sci. 4 4, 39-61. https://doi.org/DOt10.1146/annurev-marine120710-100935.

Tamura, K., Stecher, G., Peterson, D., Filipski, A., Kumar, S., 2013. MEGA6: molecular evolutionary genetics analysis version 6.0. Mol. Biol. Evol. 30, 2725-2729. https:/l dol.org/10.1093/molbev/mst197.

Tomanek, L, 2010. Variation in the heat shock response and its implication for predicting the effect of global climate change on species' biogeographical distribution ranges and metabolic costs. J. Exp. Biol. 213, 971-979. https://doi.org/10.1242/jeb. 038034 .

Traylor-Knowles, N., Rose, N.H., Sheets, E.A., Palumbi, S.R., 2017. Early transcriptional 
responses during heat stress in the coral Acropora hyacinthus. Biol. Bull. 232, 91-100. https://doi.org/10.1086/692717.

van de Water, J.A.J.M., Lamb, J.B., van Oppen, M.J.H., Willis, B.L., Bourne, D.G., 2015, Comparative immune responses of corals to stressors associated with offshore reefbased tourist platforms. Conserv. Physiol. 3, 1-13. https://doi.org/10.1093/ conphys/cov032.

Vargas-Yáñez, M., Jesús García, M., Salat, J., García-Martínez, M.C., Pascual, J., Moya, F., 2008. Warming trends and decadal variability in the Western Mediterranean shelf. Global Planet. Change 63, 177-184. https://doi.org/10.1016/1.gloplacha.2007.09. Global

Venn, A.A., Quinn, J., Jones, R., Bodnar, A., 2009. P-glycoprotein (multi-xenobiotic resistance) and heat shock protein gene expression in the reef coral Montastraea franks in response to environmental toxicants. Aquat. Toxicol. 93, 188-195. https://doi org/10.1016/j.aquatox.2009.05.003.

West, J.M., Salm, R.V., 2003. Resistance and resilience to coral bleaching: implication for coral reef conservation and management. Conserv. Biol. 17, 956-967. https://doi. org/10.1046/j.1523-1739.2003.02055.x.

Yost, D.M., Wang, L.H., Fan, T.Y., Chen, C.S., Lee, R.W., Sogin, E., Gates, R.D., 2013. Diversity in skeletal architecture influences biological heterogeneity and Symbiodinium habitat in corals. Zoology 116, 262-269. https://doi.org/10.1016/] zool. 2013.06.001.

Zhang, Y., Zhou, Z., Wang, L., Huang, B., 2018. Transcriptome, expression, and activity analyses reveal a vital heat shock protein 70 in the stress response of stony coral Pocillopora damicornis. Cell Stress Chaperones 70, 1-11. https://doi.org/10.1007/ s12192-018-0883-4. 